\title{
A SIMULATION MODEL FOR ROBOT'S SLIP DISPLACEMENT SENSORS
}

\author{
Yuriy Kondratenko ${ }^{1,2)}$, Oleksandr Gerasin ${ }^{2)}$, Andriy Topalov ${ }^{2)}$ \\ 1) Petro Mohyla Black Sea National University, 10 68th Desantnykiv st., Mykolaiv, 54003, Ukraine \\ y_kondrat2002@yahoo.com \\ ${ }^{2)}$ National University of Shipbuilding, 9 Heroes of Ukraine ave., Mykolaiv, 54025, Ukraine \\ oleksandr.gerasin@nuos.edu.ua,topalov_ua@ukr.net
}

\begin{abstract}
This paper deals with a simulation model of slip displacement sensors for the object slip signals' registration in the adaptive robot's gripper. The study presents the analysis of different methods for slip displacement signals detection, as well as authors' solutions. Special attention is paid to the investigations of the developed sensor with the resistive registration element in rod type structure of sensitive elements, which is able to operate in harsh and corrosive environments. A sensing system for the object slip signals' registration in the adaptive robot's gripper with a clamping force correction is developed for proposed slip displacement sensor with multi-component resistive registration elements. The hardware implementation of the sensing system for slip signals' registration and obtained results are considered in details. The simulation model of the proposed slip displacement sensor based on polytypic conductive rubber is modeled by Proteus software. The intelligent approaches with the use of a field programmable gate array (FPGA) and VHDL-model to the sensing system designing allow to define the slippage direction in slip displacement sensor based on resistive registration elements. Thus, this expands the functionality of the developed sensor. Copyright (C) Research Institute for Intelligent Computer Systems, 2016. All rights reserved.
\end{abstract}

Keywords: slip displacement sensor, adaptive robot, registration element, electrical resistance, capacitance, simulation, Proteus, slippage direction, VHDL-model, timing diagrams.

\section{INTRODUCTION}

A significant number of robotic systems belongs to a control objects class, conditions of their functioning are randomly changed. This is especially true that adaptive robot grippers operating in the dynamic environment, where manipulated objects often accidentally get into a robot work area. The objects may differ in the parameters (mass, geometrical dimensions, material, surface roughness, etc.), which can change during the execution of robot manipulation operations [1-3]. Besides, the slipping problem is typical for adaptive mobile robotic complexes and systems designed for technological operations on the inclined and vertical surfaces, such as: cleaning, painting, welding, inspection and others [4-7]. In this case slippage indicates the necessity of increasing the clamping force to the work surface (ship hulls, concrete walls, storage tanks, etc.)

For the successful solving of the problem robotic system must be able to recognize objects using their own tactile sensory systems. In robotics slip displacement sensors (SDS) are installed in gripping devices and used to create the parameters clamping force corresponding to the object's parameters which is especially important during manipulation of fragile objects $[3,8]$.

The mandatory requirements for the gripping devices include reliable capturing and object holding, stable positioning and inadmissibility of the object damage or destruction [1].

In some cases, the object clamping force should be automatically changed depending on the detail's mass. Gripping devices structures for capturing and positioning of undirected objects have recently been developing [9-10]. Furthermore, the great attention is paid to modern sensing systems of adaptive robots and information technologies for output sensors signals' processing [9-12]. Also, such systems intellectualization is an advanced approach for increasing the efficiency of SDS [13].

The aim of this work is to develop the sensor for slip signals' registration used in the construction of adaptive robots capable to work in dusty or aggressive environments, to simulate the developed slip displacement sensor with multifunctional registration elements based on polytypic conductive rubber using software Proteus and to research opportunities of the slippage direction defining of proposed intelligent sensory system with using a 
field programmable gate array (FPGA) and VHDLmodel.

\subsection{THE SLIPPAGE SIGNAL DETECTION IN ROBOTIC SYSTEMS}

As usual, the slippage signal detection in robotic systems is accomplished either in the trial motion or in the regime of continuous lifting of the robot arm by identification slipping between the gripper fingers (or sponges). In some cases, during the process of trial motions, it is necessary to make a series of trial motions for creating the required clamping forces $F_{n}$ or $F_{n r}=k F_{d}$, where $k$ is a coefficient which impacts the reliability of the object motion (by the robot arm) moving on the required path, $k>1$.

According to Fig. 1, the robot creates a minimal value of clamping force $F_{\min }$ in time moment $t_{1}$ [13]. Then step by step robot moves an object at vertical distance $\Delta x$ and increases the clamping force $\left(F\left(t_{1}\right)+\Delta F\right)$ if the slip displacement signal appears. The grasping surface of the object is limited by value $x_{\max }$. The first series of trial motions is finished in time moment $t_{2}$, when $x=x_{\max }$. After that, the robot decompresses the fingers $\left(t_{2} \ldots t_{3}\right)$, moves the gripper $\left(t_{3} \ldots t_{4}\right)$ to the initial position and creates $\left(t_{4} \ldots t_{5}\right)$ the initial value of the clamping force $F\left(t_{5}\right)=F\left(t_{2}\right)+\Delta F=F_{1}$ for the beginning of a second stage or second series of trial motions [13].
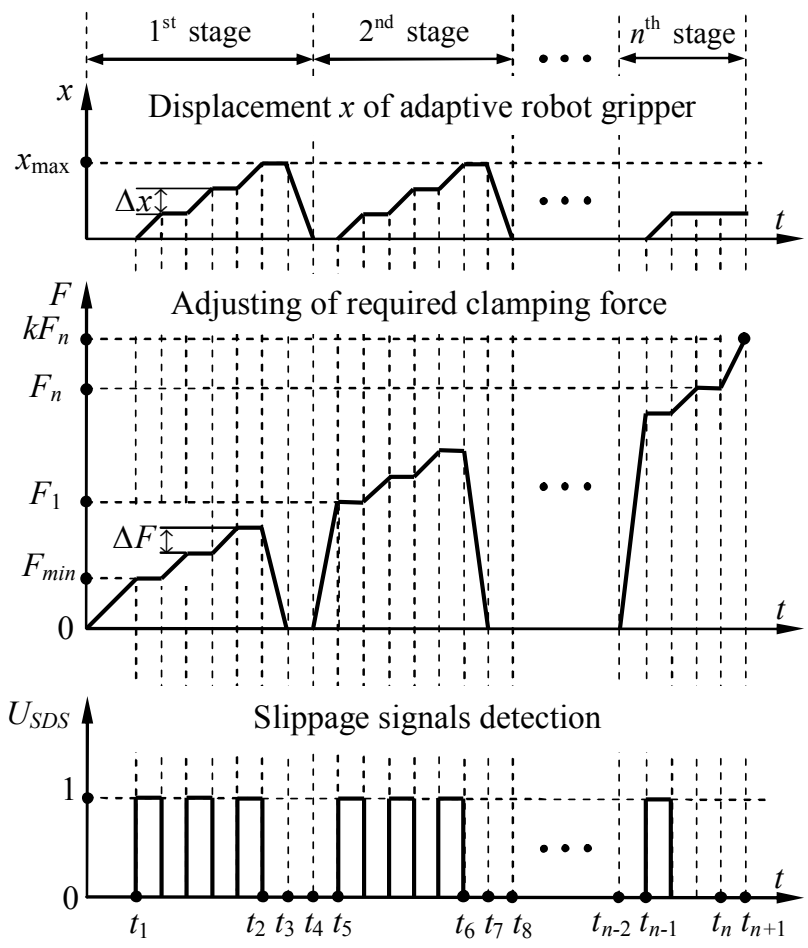

Fig. 1 - Series of trial motions and increasing clamping force $\boldsymbol{F}$ according to object slippage

\subsection{ANALYSIS OF MODERN METHODS FOR SLIP SIGNALS' REGISTRATION}

SDS registers the slip signal when the clamping force value of the gripper jaws does not correspond to the manipulated object mass.

Thus, SDS registers the slip signal if the clamping force value of the gripper sponges does not correspond to the manipulated object mass. So, slip displacement signal can be registered by various methods, let's consider the main ones [9, 10, 13-22].

Vibration detection. The method is based on the vibration detection in the sensing element when the object is slipping $[10,14]$.

Rolling motion registration. The method is based on the object displacement transformation from the vertical direction in rolling motion of sensing element like cylindrical roller with an elastic coating $[10,16,22]$.

Definition pressure changes gradient. The method is based on the changes in pressure distribution registration between the gripper fingers at the object slipping [17].

Impact-sliding vibrations detection. The method is in vibrations registration object slipping by fluid pressure changing [10].

Fixing and shift register object slippage using video surveillance [15]. The method means using location or video sensors.

The method of data acquisition by means of the photoelastic effect. In this method, the sensitive skin deformations under the influence of applied force form voltage in photoelastic system [18].

Measurement of friction between the object and gripper sponges. The method provides registration of the moment of transition from static to dynamic friction [10].

Registration of acceleration. The method is implemented using two accelerometers, one of which responds to the absolute acceleration gripper, and another senses the acceleration of the sensitive plate springing when the detail is slipping [13].

Detection of the interference pattern changes. The method is based on the intensity changes reflected from the moving surface of the interference pattern [10].

Fixing sensitive elements on the manipulated object. The method registers the sensitive elements displacement relative to the gripper when object is slipping [19].

Registration configuration changes sensitive elements. The method is based on the registration of parameters of elastic sensitive elements (eg, conductive rubber) when their configuration and electrical resistance change $[13,19,20,22]$. 
Registration angular deviation of sensitive element. There are different variants of this method implementation: using conductive rods, moreover rod's deviation at object slipping leads to closure of the circuit; using elastic rods, angular deviation which may be registered by capacitive or magnetic type sensors $[1,10]$.

Recording oscillatory circuit parameters. The method bases on a change in the oscillatory circuit inductance while the object slips $[10,13,21]$.

The choice of the registration method is determined by the robot's appointment, requirements for speed and noise immunity, environmental peculiarities and the measuring system resolution.

\section{ADVANCED SDS WITH SENSITIVE ELEMENTS BASED ON CONDUCTIVE RUBBER}

The paper presents developed by the authors sensor for registration signals slippage, which is based on registration of angular deflection sensitive element, which occurs when slippage is present. In turn the registration elements are offered to construct with conductive rubber using.

\subsection{CONDUCTIVE RUBBER ELEMENTS IN ROBOTIC MEASUREMENT SYSTEMS}

Sensor systems based on conductive rubber are widely used in modern adaptive robotic sensing systems [19, 20, 23-25]. For example, in contrast to capacitive sensors, such devices are significantly less sensitive to environmental influences, including electromagnetic fields.

Pressure-sensitive conductive rubber is a material made of non-conductive elastomer, in which electric conductive particles are distributed homogeneously. When external force acts, the particles distribution comes into another state (contacts with each other), so paths for a flowing current, and thereby the resistance, change as a result of producing strain in the material [25].

Deformations of conductive rubber with black carbon as a filler is investigated in [26]. Authors measure a volume electrical resistance $\rho_{\mathrm{V}}$ using the potentiometric measuring cell in the process of stretching. Samples in the form of strips (100x10x2 $\mathrm{mm}$ ) are clamped between the current-supplying electrodes and stretched using a micrometer screw. The number of stretching cycles recorded by the counter installed on the measuring cell. Test results show (Fig. 2) that the value of rubber $\rho_{\mathrm{V}}$ decreases monotonically and $\rho_{\mathrm{V}}$ changes show hysteresis. Also stretching and recovery curves are practically the same starting from the second cycle [26]. In general electrical impedance of conductive rubber samples amounts from $10^{2}$ to $10^{4} \mathrm{Ohm} \cdot \mathrm{cm}$ [27].

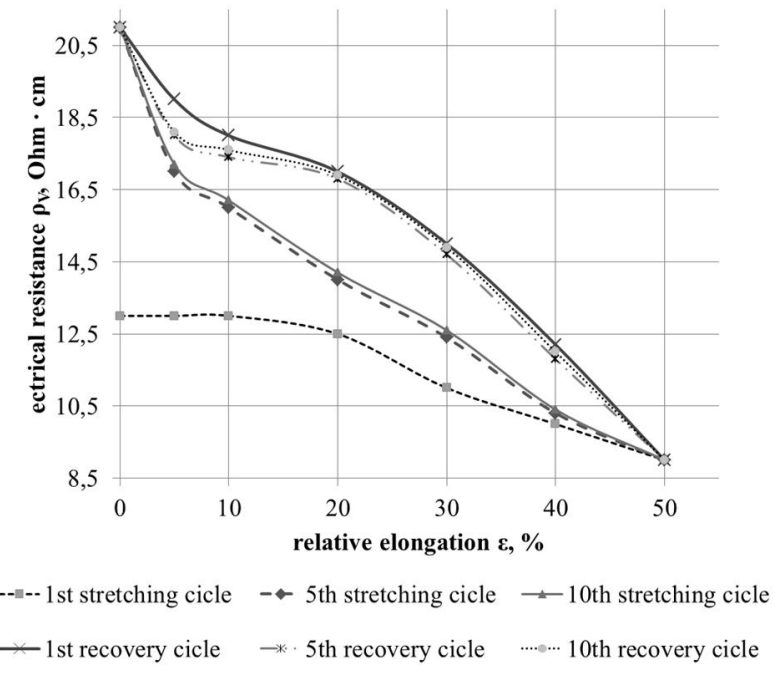

Fig. 2 - Dependence $\rho_{v}$ of conductive rubber from relative elongation

The SDS is considered in [23] for robot adaptation to the clamping details weight, which dimensions can significantly exceed the size of gripper fingers (Fig. 3).

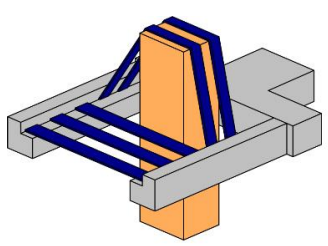

a)

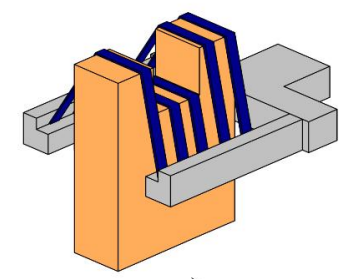

c)

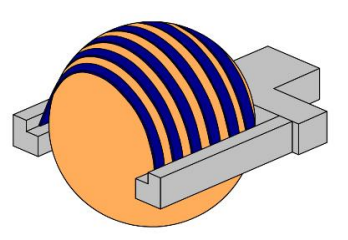

b)

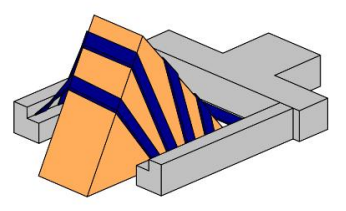

d)
Fig. 3 - Adaptive robot gripper with SDS based on electro-conductive plates at various shape details capturing: prismatic (a), spherical (b), combined prismatic (c), prismatic with a triangular profile (d)

During such details capturing plates, made of conductive rubber, stretch and bend around the object contours, then control unit stores the plates electrical resistance value $R(t-\tau)$. In case of the detail slippage presence the plate's 4 configuration changes and, consequently, their electrical resistance changes too, so it becomes $R(t)$. At the same time changes in plate's electrical resistance

$$
\Delta R=R(t)-R(t-\tau)
$$


are registered, and a control unit gives the signal $U_{\text {inc }}$ to the fingers drive for clamping force $F$ increasing.

Also, the tactile transducer as a matrix of electrodes, covered by a layer of pressure sensitive conductive rubber is considered in [19]. Electrical resistance changes are measured with a resistive voltage divider and further using a microcontroller.

\subsection{SDS WITH CONDUCTIVE RUBBER MULTIFUNCTIONAL REGISTRATION ELEMENTS}

The method of data acquisition with registration of the sensitive elements configuration changes [23] is used in the proposed sensor with multi-component registration element based on the conductive rubber.

The SDS (Fig. 4, a) includes a rod, located in conical groove on jaw of an adaptive gripper, a tip and the multicomponent registration element $[3,23]$.
Each individual component of the multicomponent registration element is designed as elastic plates made of conductive rubber.

The drive control block input is connected with the output of the clamping force correction block 12 that includes sequentially connected the multi measurement block 13, the first adder 14, the second adder 15 and a threshold element 16. The multi measurement block is designed as a measuring bridge with variable resistors and is powered by a voltage source.

Some components of the registration element in the form of elastic plates made of conductive rubber connected to the relevant measuring bridge shoulders. Those elastic plates made of conductive rubber directly represent resistors with variable electrical resistances.

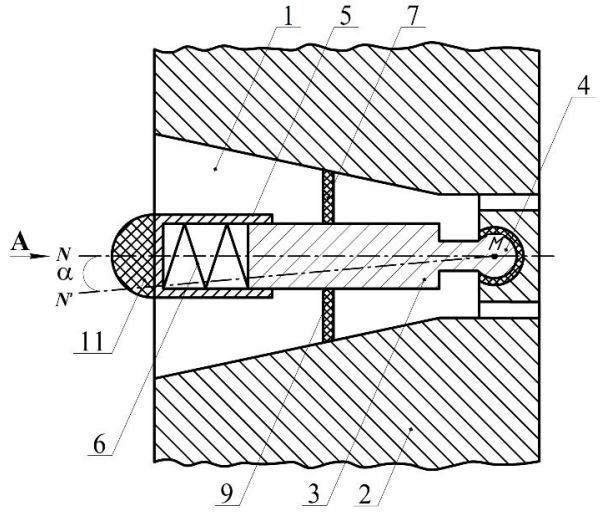

a)

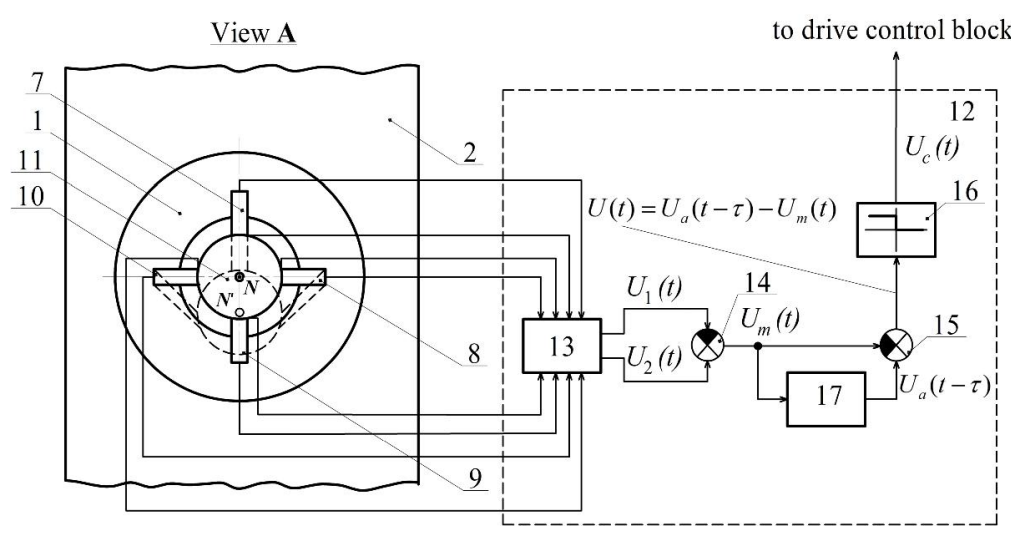

b)

Fig. 4 - Proposed SDS with electro-conductive plates: mechanical (a) and electronic (b) components: 1 - conical groove; 2 - adaptive robot gripper sponge; 3 - rod, 4 - spherical hinge; 5 - tip; 6 - spring; 7,8,9,10 - plates made of conductive rubber; 11 - tip working surface; 12 - clamping force correction block; 13 - multi measurement unit; 14 - the first adder; 15 - the second adder; 16 - threshold element; 17 - delay element

\section{REAL TIME SIMULATION OF SDS WITH CONDUCTIVE RUBBER SENSITIVE ELEMENTS}

\subsection{DESCRIPTION OF THE SENSOR SYSTEM MODEL WITH PROPOSED SDS}

For the stabilization of the rod position in the SDS four identical plates made of conductive rubber are used (Fig. 4, b). These plates are used as sensing elements that change their electrical resistance due to deformation (compression or tension plates at moving rod with tip), at the same time they balance the rod in a free position in the center of the conical groove. So, after the voltage supply for plates made of conductive rubber in case of tension or compression a signal is formed as a potential difference, which shows (indicates) the fact of an object slip between the gripper jaws. The plates made of conductive rubber were connected as symmetrical Uitson bridge circuit to compensate the individual components and complete error exclusion constant component of the voltage measuring $[3,28$ 31].

Simulation of the proposed SDS electronic part was held using developed sensing system for the key points of the scheme in Proteus software (Fig. 5).

Measuring bridge voltage $U_{m}$ can be represented as a voltage difference $U_{m}=U_{1}-U_{2}$, it depends on the supply voltage $U_{0}$ and resistors $R_{1}, R_{2}, R_{3}, R_{4}$ (RV1-RV4 at Fig. 5) which correspond to individual electrical resistance components of the multicomponent registration element [29].

$$
U_{m}=\frac{R_{1}}{R_{1}+R_{4}} U_{0}-\frac{R_{2}}{R_{2}+R_{3}} U_{0}
$$


The measurement voltage is calculated using the first adder, which in turn is a circuit instrumentation operational amplifier. It calculates the voltage difference $U_{m}=U_{1}-U_{2}$. The instrumentation amplifier MAXIM MAX4194 is used for simulation.
The output signal of the first adder $U_{m}$ is fed simultaneously to inverting input of the second adder, which is a circuit operational amplifier LM324, and through delay element to the noninverting input of the second adder [23].

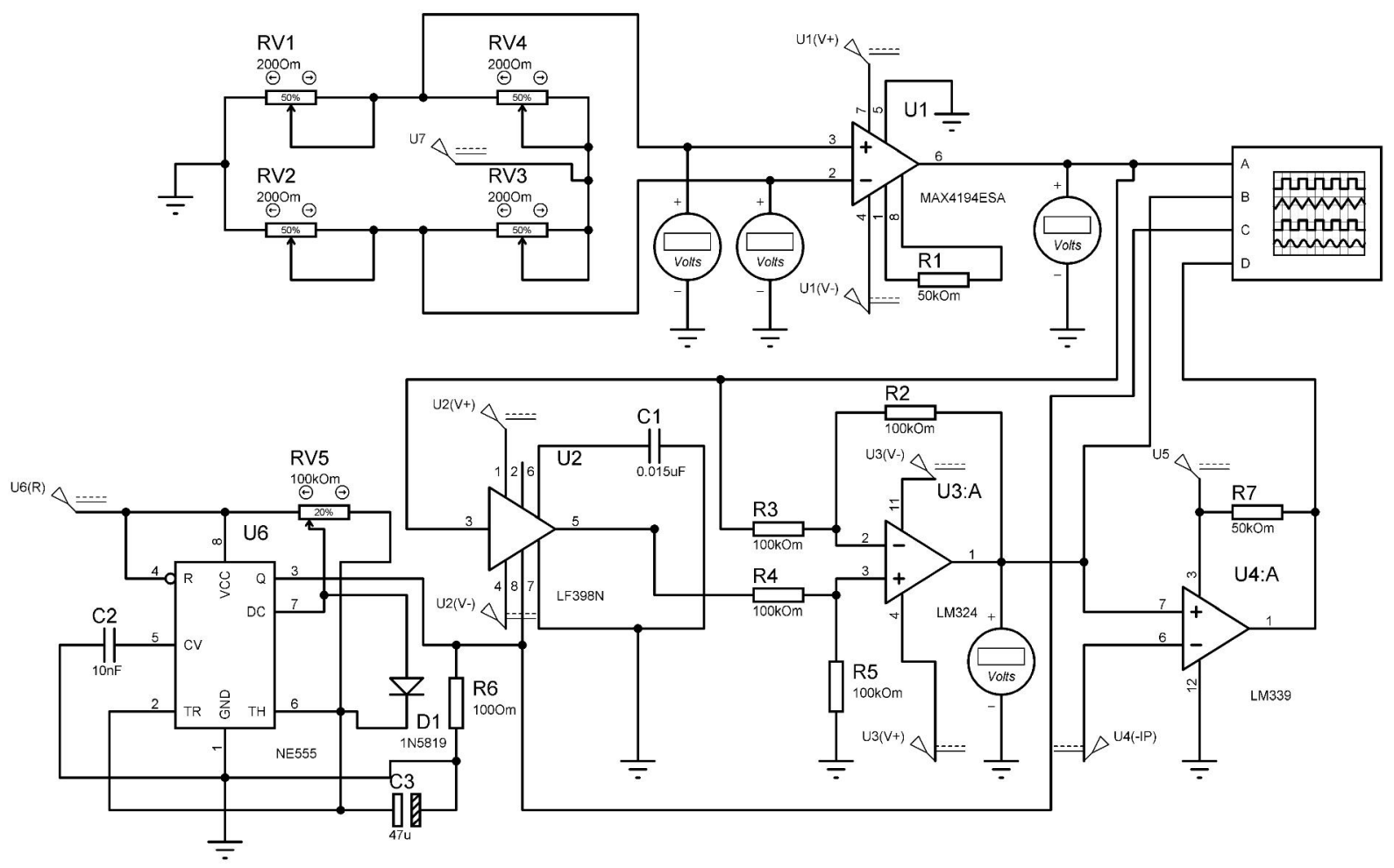

Fig. 5 - Simulation model

The analog signal delay element is realized by sampling and storage device (SSD) LF398 with storage capacitor. Moreover, a square wave generator for SSD is based on the chip NE555. The output high-level duration $t_{H}$ [32] for our scheme (Fig. 5) can be calculated as follows:

$$
t_{H}=0.69 \varepsilon R_{\mathrm{RV} 5} C_{\mathrm{C} 3}
$$

and low-level duration $t_{L}$

$$
t_{L}=0.69(1-\varepsilon) R_{\mathrm{RV} 5} C_{\mathrm{C} 3},
$$

which together make the square wave generator period $T$

$$
T=t_{L}+t_{H}=0.69 R_{\mathrm{RV} 5} C_{\mathrm{C} 3},
$$

where $R_{\mathrm{RV} 5}$ - resistance of the variable tuning resistor RV5; $C_{\mathrm{C} 3}$ - capacitance of the capacitor $\mathrm{C} 3$ at Fig. 5, $\varepsilon$-resistances ratio of $R_{\mathrm{RV} 5}$ parts.
Output SSD voltage $U_{a}(t-\tau)$ reiterates the value of the input voltage with delay in a certain period of time $\tau$, which corresponds to the delay between adaptive robot trial motions. Herewith the second adder output signal is formed:

$$
U(t)=U_{a}(t-\tau)-U_{\text {out }}(t),
$$

which corresponds to the difference between the output signals of the first adder before $U_{a}(t-\tau)$ and after $U_{\text {out }}(t)$ trial motion.

The output signal of the second adder, when slippage takes place, gets only positive values $U(t)>0$ and comes to the threshold element (based on LM339) input, ideal static characteristic of which is as follows:

$$
U_{C}(t)=\left\{\begin{array}{l}
1, \text { if } U(t)>0 \\
0, \text { if } U(t) \leq 0
\end{array} .\right.
$$

Hardware implementation of the sensing system as a printed circuit board has been developed and is presented at Fig. 6. 


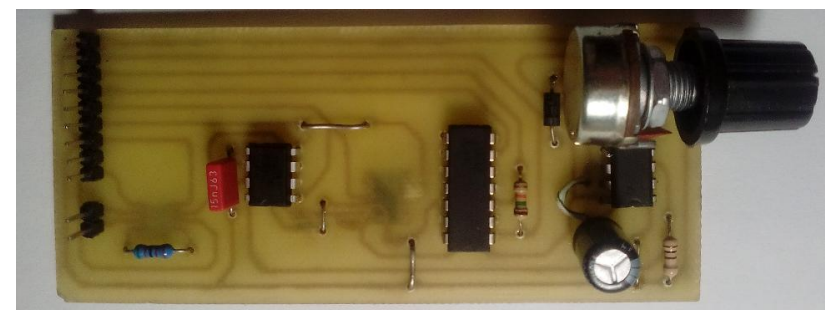

a)

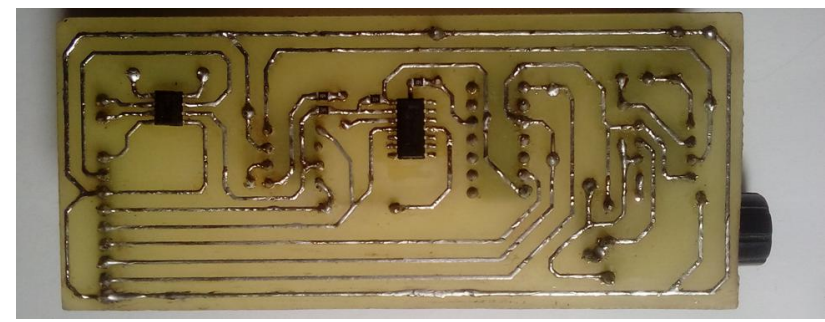

b)

Fig. 6 - The top (a) and bottom (b) views of printed circuit board for developed sensor system

The role of the threshold element takes comparator working without feedback control used for digital microcircuits with high speed, including overload. Thus at the output signal threshold element formed logical one $U_{C}(t)=1$ that indicates the presence of slip. This signal fed to the sponges block drive, which generates the appropriate command signal to increase the clamping force for a preset value.

The printed circuit board (Fig. 6) of developed sensor system was designed by authors based on simulation model (Fig. 5). Each conductive rubber plate was presented by variable resistor (not shown at Fig. 6). The measurement bridge is removed by 30 $\mathrm{cm}$ from printed circuit board and connected by twisted-pair cable.

\subsection{SDS'S MODELLING RESULTS DISCUSSION}

Computer simulation was carried out at low square wave generator frequency $(0.22 \mathrm{~Hz})$ to the real-time unbalance measuring bridge in the program and in the real scheme (Fig. 6). Transient processes were traced in the scheme by real digital (Fig. 7) and virtual from Proteus software (Fig. 8) oscilloscopes.

Whether measuring bridge balance is lost (when the rod rejected in the slipping direction of the object), in this case conductive elastic plate 9 resistance $\left(R_{1}\right)$ decreased (plate 9 shrinked) and plate 7 resistance $\left(R_{4}\right)$ increased (plate 7 stretched). The plates 8 and 10 were stretched at about the same level, according to their electrical resistances $\left(R_{2}\right.$, $R_{3}$ ) increased at the end of the trial motion and became approximately equal.
At this time, the voltage at the output of the first adder $U_{m}(t)$ is reduced to a certain value (time diagram with yellow line at Fig. 7, a). The first adder based on instrumentation amplifier shows good noise immunity and the stability of the measured quantity. The voltage at the output of the second adder $U(t)$, which calculates the difference between the direct signal and the signal from the first adder with delay (blue line).

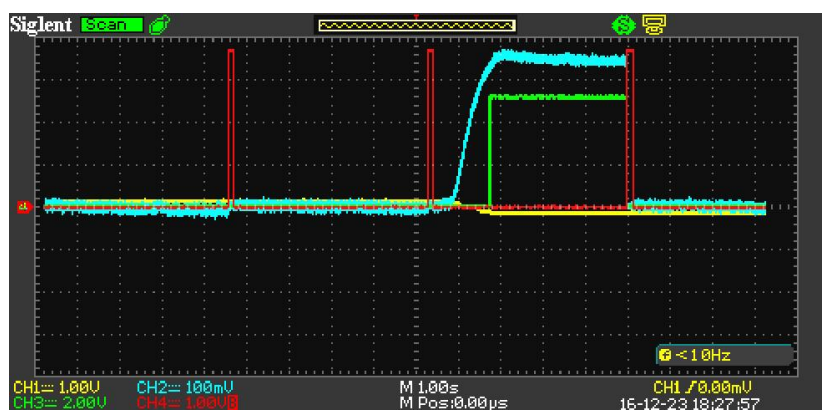

a)

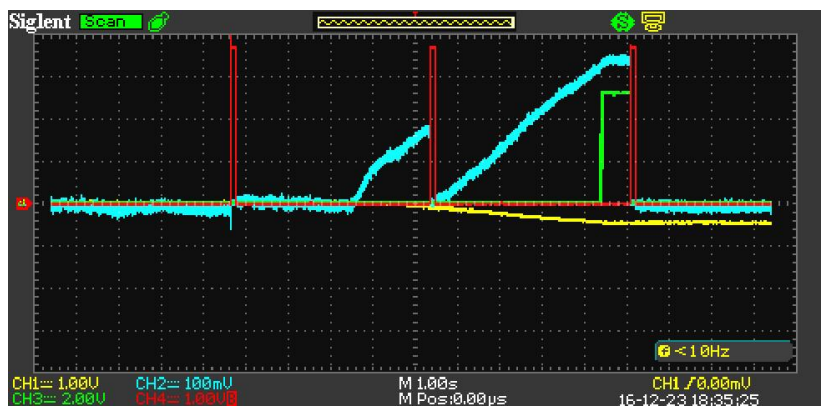

b)

Fig. 7 - The SDS experimental voltage time diagrams with one (a) and two (b) square wave generator periods of slippage presence by lines: yellow $-U_{m}(t)$, blue - $U(t)$, green - $U_{c}(t), \operatorname{red}-U_{T}(t)$

When the repeated charge storage capacitor takes place, the SSD switches to trace, as evidenced by the indicating a signal transition $U_{T}$ from a logical zero to a logical one (red line), respectively, the output voltage of the second adder is equal to zero. It should be noted, that charging time much less than discharging time of storage capacitor. Therefore storage capacitor has time to keep the stored value of voltage without losses. Output comparator voltage $U_{C}$ (green line) goes into a logical one only if the second adder voltage increases from zero to positive values that indicates the slip presence. The comparator threshold is set equal $300 \mathrm{mV}$.

The second adder based on an ordinary operational amplifier shows light noise (less than $25 \mathrm{mV}$ ), which doesn't affect on slip signal registration. Tests results (Fig. 7, b) also show developed sensor operability whether slippage occurs between timer events. In this case comparator gives $5 \mathrm{~V}$ at the next square wave generator period. 
So, there is no need to align the measuring bridge shoulders for each robot gripper trial motion and to capture from the beginning.

Significant influence on the sensitivity of the measuring bridge is rendered by physical properties of conductive rubber. As can be seen from simulation results (Fig. 8), the output voltage of the first adder $U_{m}(t)$ variously changes depending on the volume conductivity of the electro-conductive rubber plates $[25,26]$.

The measurement bridge balance is quickly lost by increasing the sensitivity of the conductive plates at the same rode displacements which in turn affects the data processing of system slipping signal. So, at the same voltage set point comparator has a different delay time $t_{d 1}, t_{d 2}, t_{d 3}$, wherein $t_{d 3}<t_{d 2}<t_{d 1}$ (at Fig. 8). This feature allows to improve the performance of the proposed sensor using more sensitive electro-conductive rubber.
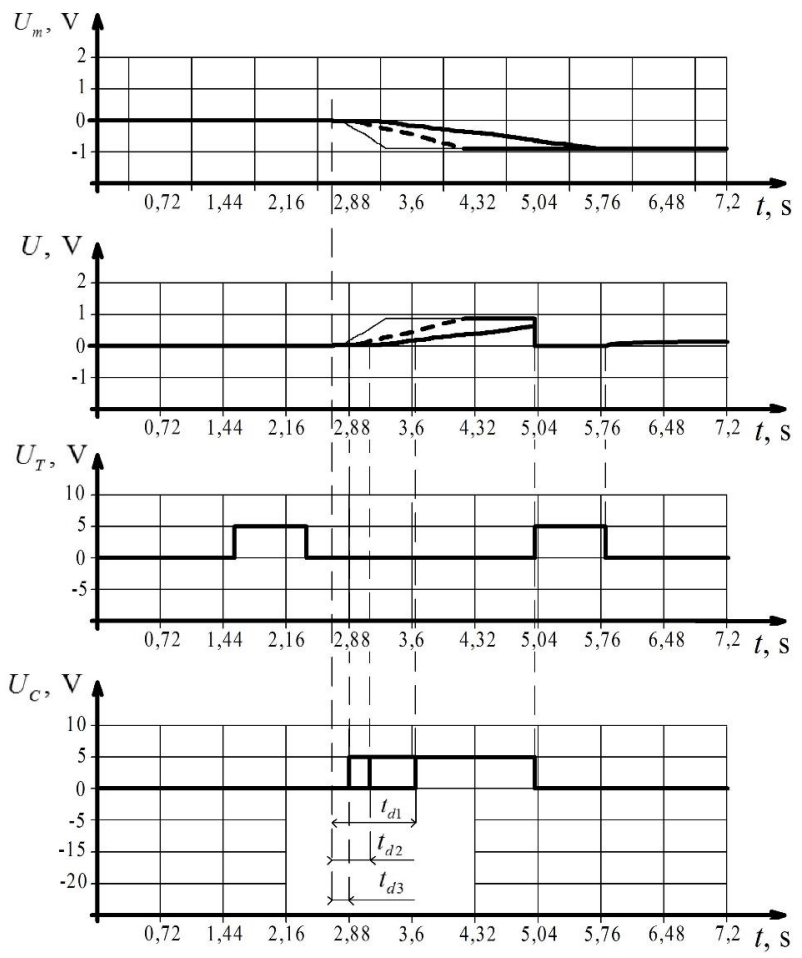

Fig. 8 - The SDS simulation time diagrams with analysis of registration element sensitivity

\section{INTELLIGENT SDS FOR IDENTIFICATION OF SLIPPAGE DIRECTION IN ROBOT GRIPPER}

\subsection{METHOD OF THE SLIPPAGE DIRECTION IDENTIFICATION}

From time to time, the robot's gripper may be faced with an obstacle when the robot moves a manipulation object in dynamic environments according to the preplanned trajectories. The obstacles can appear randomly in the dynamic working area of the intelligent robot $[23,33]$. As a result of the collision between the robot gripper and the obstacle, object's slippage may appear if the clamping force $F$ is not enough for reliable fixation of object between the gripper's fingers. The direction $\{N, N E, E, S E, S, S W, W, N W\}$ of such slip displacement of the object depends on the position of the obstacle in the desired trajectory (Fig. 9).

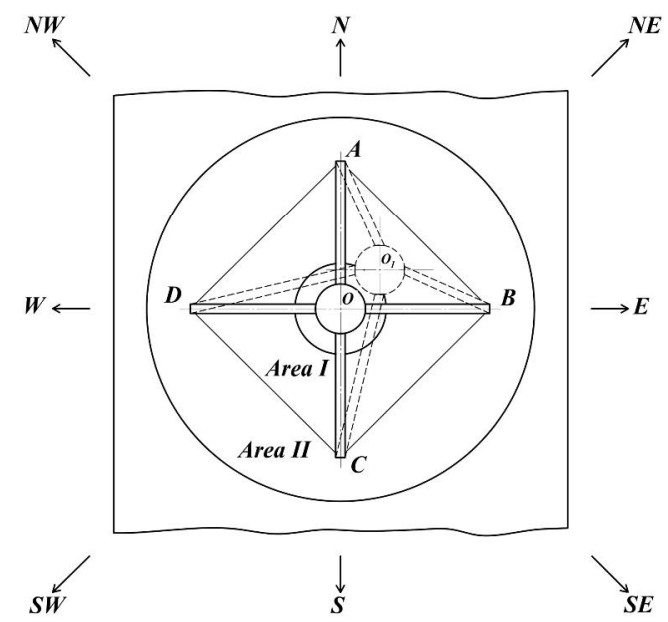

a)

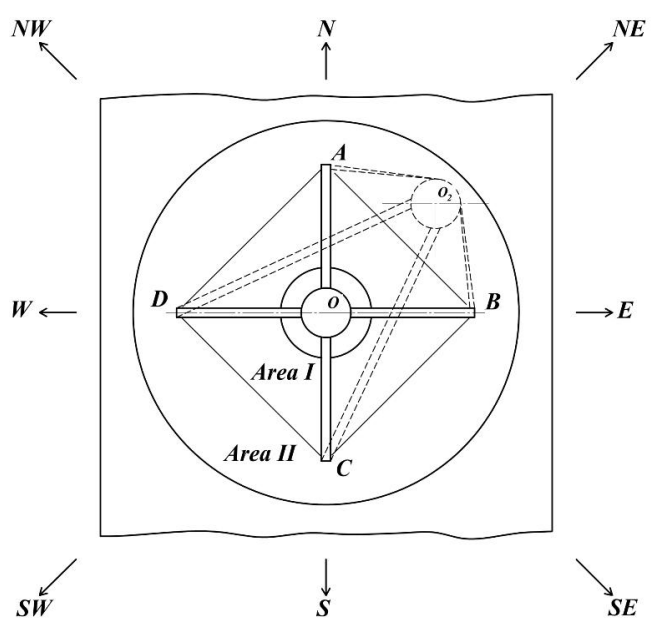

b)

Fig. 9 - The possible locations of the rod tip in the conical groove: positioning at a point $O_{1}$ in area $I$ (a) and at a point $O_{2}$ in area II (b)

Table 1 determines the functional dependence between the direction of object slippage (Fig. 9), the current state of each resistance $\left\{R_{1}, R_{2}, R_{3}, R_{4}\right\}$ and the bridge measured voltage $U_{m}$, where $(>)-$ indicator of the corresponding resistance $R_{i}$, $(i=1 \ldots 4)$ increases during the object slippage process; $(<)$ - indicator of the corresponding resistance $R_{i},(i=1 \ldots 4)$ decreases during the object slippage process; $(=)$ - pair's indicator of equivalence according to conditions $R_{i}=R_{j}$, $(i=1 \ldots 4),(j=1 \ldots 4), i \neq j$ in the antecedents states.

As can be seen from Table 1, the same value of the output voltage of the measuring bridge $U_{m}$ 
corresponds to several slippage directions with the same displacement $\Delta x$ in each direction, for example $1.2 \mathrm{~V}$ corresponds to $N$ and $E$ directions. Furthermore, the Uitson bridge circuit has difficulty with slippage registration in intermediate directions $S E$ and $N W$, which are identified as $0 \mathrm{~V}$.

Table 1. The measuring bridge circuit output signals $U_{m}$ with the same value of rod displacement in different directions

\begin{tabular}{|c|c|c|c|c|c|}
\hline $\begin{array}{c}\text { Direction of } \\
\text { slippage }\end{array}$ & $\boldsymbol{R}_{\mathbf{1}}$ & $\boldsymbol{R}_{\mathbf{2}}$ & $\boldsymbol{R}_{\mathbf{3}}$ & $\boldsymbol{R}_{\mathbf{4}}$ & $\begin{array}{c}\text { Measurement } \\
\text { voltage } \boldsymbol{U}_{\boldsymbol{m}}, \boldsymbol{V}\end{array}$ \\
\hline $\mathrm{S}$ & $<$ & $=$ & $=$ & $>$ & -1.2 \\
\hline $\mathrm{N}$ & $>$ & $=$ & $=$ & $<$ & 1.2 \\
\hline $\mathrm{W}$ & $=$ & $>$ & $<$ & $=$ & -1.2 \\
\hline $\mathrm{E}$ & $=$ & $<$ & $>$ & $=$ & 1.2 \\
\hline $\mathrm{SE}$ & $=$ & $=$ & $>$ & $>$ & 0 \\
\hline $\mathrm{SW}$ & $=$ & $>$ & $=$ & $>$ & -1 \\
\hline $\mathrm{NE}$ & $>$ & $=$ & $>$ & $=$ & 1 \\
\hline $\mathrm{NW}$ & $>$ & $>$ & $=$ & $=$ & 0 \\
\hline
\end{tabular}

The potentiometric measurement circuit [29] may be used for determining the slippage direction. However, this approach requires additionally components for each conductive plate voltage measuring. Thus, come back to Uitson measuring bridge and consider not a difference between $U_{1}$ and $U_{2}$ but each of these voltages $\left(U_{1}\right.$ and $\left.U_{2}\right)$ separately.

Two production rule "IF-THEN" bases [13] are used considering sensor features connected with uneven change in the resistance of the conductive plates at the rod deviation in the entire conical groove. The first base (Table 2) describes slippage determination whether the tip 11 placed within the quadrangular geometric area ABCD limits (area I at Fig. 9, a). The second base (Table 3) describes slippage determination whether the tip 11 placed between outside the quadrangular geometric area $A B C D$ limits and the inner surface of the conical groove (area II at Fig. 9, b). The previous state $U_{i}^{\prime}$ (for area $\mathrm{I}$ at Fig. 9, a) is given for comparison $[13,34]$.

Table 2. The base of production rules "IF-THEN" for the slip displacement direction identification in area $I$.

\begin{tabular}{|c|c|c|c|}
\hline \multirow{2}{*}{$\begin{array}{c}\text { No. } \\
\text { of } \\
\text { ruler }\end{array}$} & \multicolumn{2}{|c|}{ Antecedent } & Consequent \\
\cline { 2 - 5 } & $\boldsymbol{U}_{\boldsymbol{1}}$ & $\boldsymbol{U}_{\mathbf{2}}$ & Direction of slippage \\
\hline 1 & $<$ & $=$ & S (rode moves down) \\
\hline 2 & $>$ & $=$ & N (rode moves up) \\
\hline 3 & $=$ & $>$ & W (rode moves left) \\
\hline 4 & $=$ & $<$ & E (rode moves right) \\
\hline 5 & $>$ & $<$ & NE (rode moves up to the right) \\
\hline 6 & $>$ & $>$ & NW (rode moves up to the left) \\
\hline 7 & $<$ & $>$ & SW (rode moves down to the left) \\
\hline 8 & $<$ & $<$ & SE (rode moves down to the right) \\
\hline
\end{tabular}

Table 3. The base of production rules "IF-THEN" for the slip displacement direction identification in area II.

\begin{tabular}{|c|c|c|c|c|c|}
\hline \multirow{2}{*}{$\begin{array}{c}\text { No. of } \\
\text { ruler }\end{array}$} & \multicolumn{4}{|c|}{ Antecedent } & Consequent \\
\cline { 2 - 6 } & $\boldsymbol{U}_{\boldsymbol{1}}^{\prime}$ & $\boldsymbol{U}_{\boldsymbol{1}}$ & $\boldsymbol{U}^{\prime}{ }_{\boldsymbol{2}}$ & $\boldsymbol{U}_{\mathbf{2}}$ & Direction of slippage \\
\hline 1 & $>$ & $<$ & $<$ & $>$ & $\mathrm{NE}$ \\
\hline 2 & $>$ & $<$ & $>$ & $<$ & $\mathrm{NW}$ \\
\hline 3 & $<$ & $>$ & $>$ & $<$ & $\mathrm{SW}$ \\
\hline 4 & $<$ & $>$ & $<$ & $>$ & $\mathrm{SE}$ \\
\hline
\end{tabular}

Both rule bases define the functional dependence between the direction of object slippage (Fig. 9), the current states of resistances $\left\{R_{1}, R_{2}, R_{3}, R_{4}\right\}$ for each separate component of the registration element, the corresponding measurement bridge output signals $\left\{U_{1}, U_{2}\right\}$, the previous corresponding measurement bridge output signals $\left\{U_{1}^{\prime}, U_{2}^{\prime}\right\}$ (for Table 3 ), where: ">" - indicator of the corresponding signals $U_{i}$ and $U_{i}^{\prime},(i=1 \ldots 2)$ increases during the object slippage process; " $<$ " - indicator of the corresponding signals $U_{i}$ and $U_{i}^{\prime},(i=1 \ldots 2)$ decreases during the object slippage process; " $="-$ pair's indicator of equivalence according to conditions $U_{i}=U_{j}, U_{i}^{\prime}=$ $U_{j}^{\prime},(i=1 \ldots 2),(j=1 \ldots 2), i \neq j$ in the antecedents of the production rules.

The intelligent sensor system for slippage direction identification based on Table 2 and Table 3 is shown at Fig. 10. Voltage increasing and decreasing are defining by 4 threshold elements with two thresholds $a$ and $b(a>0, b<0)$ and a slippage direction determining block based on a FieldProgrammable Gate Array (FPGA), that keeps prewious state of logical inputs $X 1, X 2, X 3, X 4$ and provides slippage direction identification (output $Y$ means slippage direction) in both areas according to Fig. $9[35,36]$.

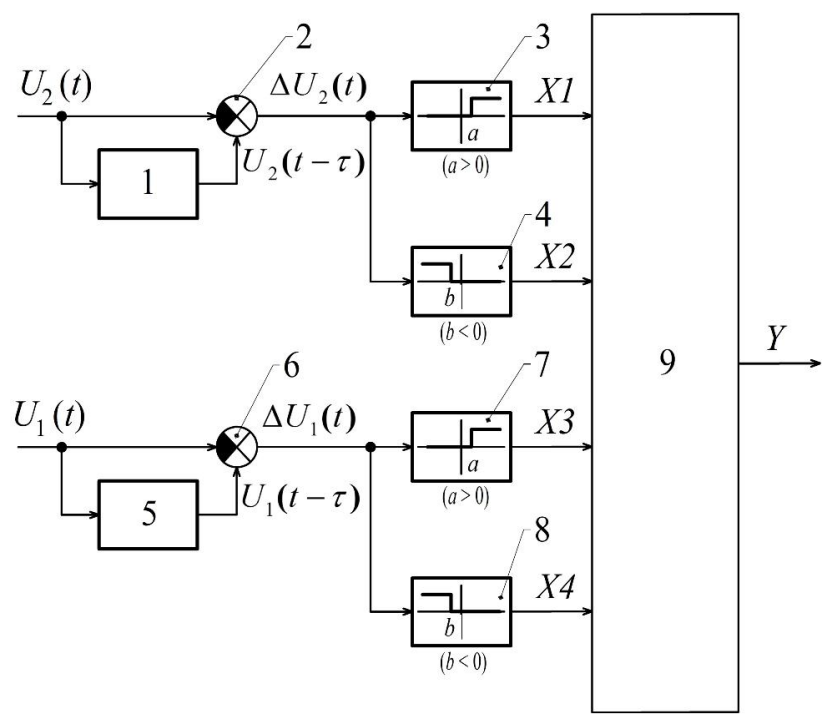

Fig. 10 - Proposed sensor system for the slippage direction identification: 1,5 - delay elements; 2,6 adders; 3, 4, 7, 8 - threshold elements; 9 - slippage direction determining block based on FPGA 
Then, all slippage direction identifications can be summarized in the Table 4 for both areas.

A transition from area I to area II at slippage direction identification is described by the next logical functions:

$$
\begin{aligned}
& \text { for NW }: Y=X 2_{-1} \wedge X 4_{-1} \wedge X 1 \wedge X 3, \\
& \text { for SW }: Y=X 2_{-1} \wedge X 3_{-1} \wedge X 1 \wedge X 4, \\
& \text { for NE : } Y=X 1_{-1} \wedge X 4_{-1} \wedge X 2 \wedge X 3, \\
& \text { for SE }: Y=X 1_{-1} \wedge X 3_{-1} \wedge X 2 \wedge X 4,
\end{aligned}
$$

where $X 1, X 2, X 3, \quad X 4$ - current states of corresponding inputs of FPGA (at the entrance to the area II); $X 1_{-1}, X 2_{-1}, X 3_{-1}, X 4_{-1}$ - previous states of corresponding inputs $(X 1 \ldots X 4)$ of FPGA (at exit from the area I).

Then a VHDL-model [37, 38] of the proposed sensing system for slippage direction identification (Fig. 11) is developed based on truth Table 4. The SDS VHDL-model in the form of block diagram consisting of logical elements is designed in computing environment Active-HDL (company Aldec Inc., USA) using the integrated editor of block diagrams BDE (Block Diagram Editor). It is important that the behavioral modeling results may be shown as timing diagrams which display and allow to analyze the state dependence of the outputs

\begin{tabular}{|c|c|c|c|c|c|c|c|c|}
\hline \multicolumn{4}{|c|}{ Inputs for area I } & \multicolumn{4}{|c|}{ Inputs for area II } & \multirow{2}{*}{$\begin{array}{c}\text { Output } \\
\text { (Direction } \\
\text { of } \\
\text { slippage) }\end{array}$} \\
\hline$X 1$ & $X 2$ & $X 3$ & $X 4$ & $X 1$ & $X 2$ & $X 3$ & $X 4$ & \\
\hline 0 & 0 & 0 & 0 & - & - & - & - & $\begin{array}{c}\text { I (initial } \\
\text { state) }\end{array}$ \\
\hline 0 & 0 & 0 & 1 & - & - & - & - & $\mathrm{N}$ \\
\hline 0 & 0 & 1 & 0 & - & - & - & - & $\mathrm{S}$ \\
\hline 0 & 1 & 0 & 0 & - & - & - & - & $\mathrm{W}$ \\
\hline 1 & 0 & 0 & 0 & - & - & - & - & $\mathrm{E}$ \\
\hline 0 & 1 & 0 & 1 & 1 & 0 & 1 & 0 & NW \\
\hline 0 & 1 & 1 & 0 & 1 & 0 & 0 & 1 & SW \\
\hline 1 & 0 & 0 & 1 & 0 & 1 & 1 & 0 & $\mathrm{NE}$ \\
\hline 1 & 0 & 1 & 0 & 0 & 1 & 0 & 1 & $\mathrm{SE}$ \\
\hline
\end{tabular}
from the inputs for different operation modes [37].

Table 4. The truth table for identification of the slip displacement direction in area I and area II.

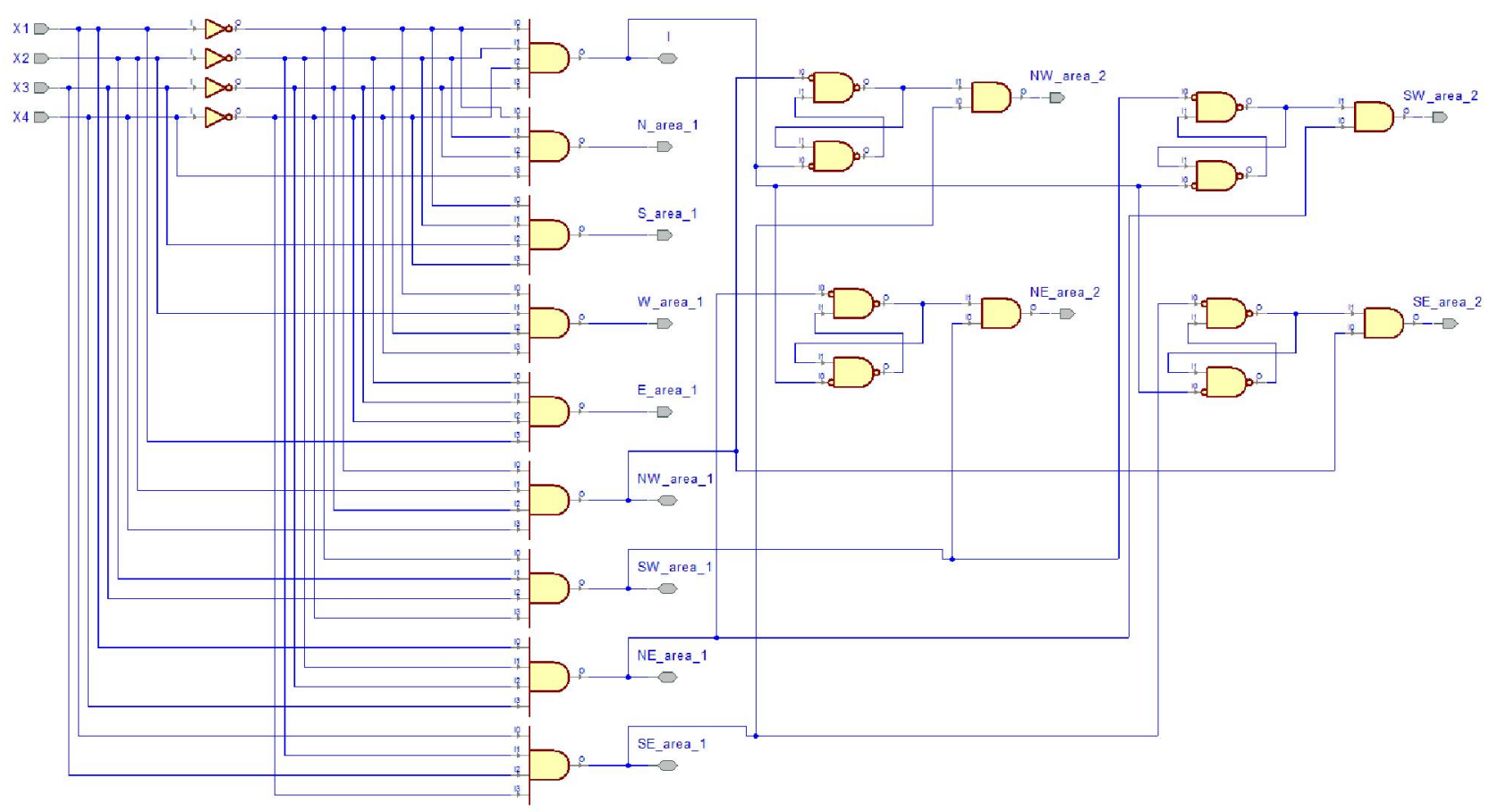

Fig. 11 - SDS VHDL-model in the form of block diagram

Let's consider computer simulation results of proposed sensing system presented at time diagrams (Fig. 12) for the rod displacements in all possible directions for area I and area II. The initial position of the rod corresponds to the level of logical one on the "I" input/output. Then slippage occurs in $N$ direction indicated as "0001" combination of inputs $X 1 \ldots X 4$ ("N area 1" row at Fig. 12) according to Table 4. So, each new rod displacement in new direction begins with the logic 1 transition to 0 at input/output "I" (throw the initial state). The same situation is observed for other slippage directions in area I.

A significant advantage of proposed slippage direction identification system is absence of additional delay for storage of previous inputs states. This task was solved by logic elements using a trigger circuit (Fig. 11). So, FPGA-based slippage 
direction determining block forms output signal during one clock pulse especially at the transition from the area I to area II (for example, from
"NW area 1" to "NW area 2" direction in "NW area 2 " highlighted zone at Fig. 12).

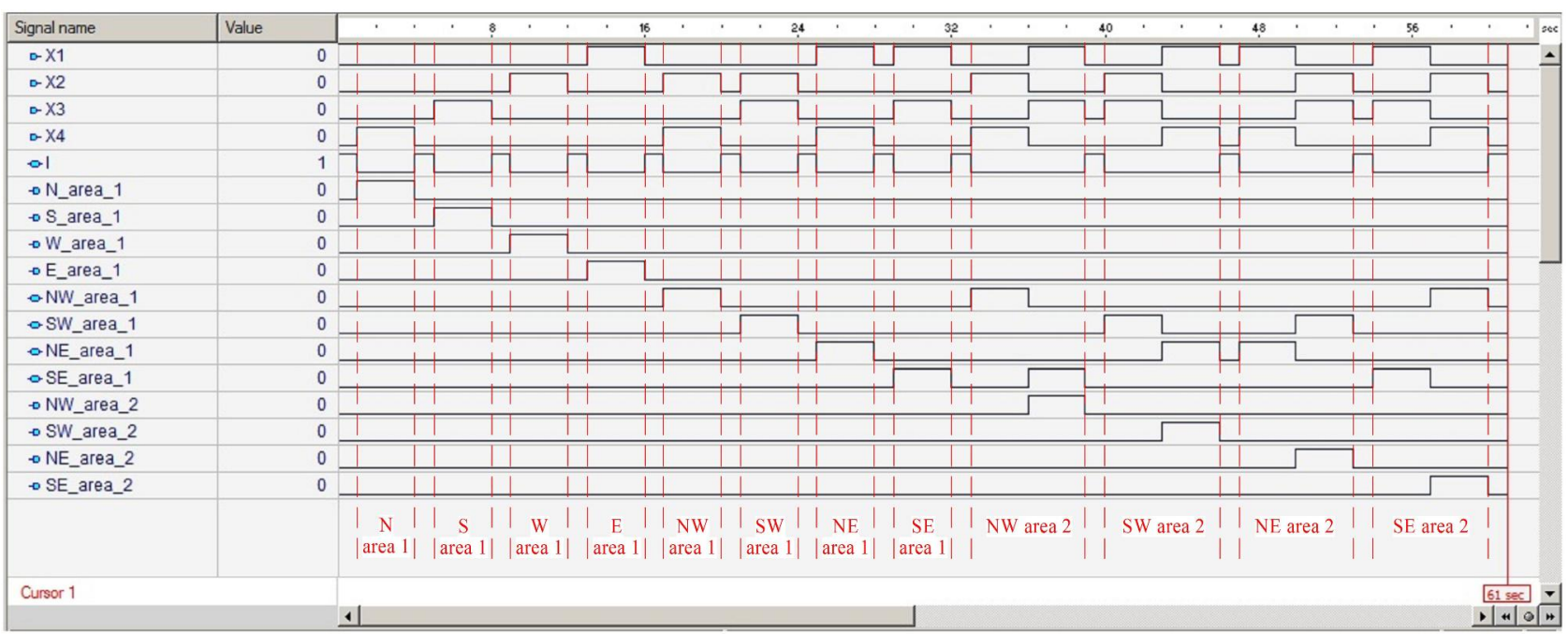

Fig. 12 - Timing diagrams for intelligent sensing system of slippage direction identification

\subsection{INTELLIGENT SDS PROPERTIES FOR ROBOT FUNCTIONING IN ENVIRONMENT WITH UNCERTAINTY}

However, for taking into account the sensor features connected with uneven change in the resistance of the conductive plates at the rod deviation in the entire conical groove should be used some adjustments. According to Fig. 9, the rod deviation in a conical groove, within the quadrangular geometric square $\mathrm{ABCD}$ (area I) from the starting spatial position (point $O$ ) to the point $O_{I}$ the plates 7 and 8 are shrinked and the plates 9 and 10 are stretched (according to Fig. 4). Upon further rod displacement in the spatial position $\mathrm{O}_{2}$, all the plates are stretched. Thus, slippage determination procedure has to compare the current measuring bridge states $U_{i},(i=1 \ldots 2)$ with the previous states $U_{i}^{\prime}$ (for area I at Fig. 9) when the tip placed between outside the quadrangular geometric area $\mathrm{ABCD}$ limits and the inner surface of the conical groove (area II at Fig. 9).

According to Fig. 13, the SDS functionality is extended due to maximum movement $x_{\max }$ increasing to new bigger value $x_{\max }^{*}$, by increasing of sensor working surface $\Delta x^{\prime}$ (in every direction) due to area II (Fig. 9):

$$
x_{\max }^{*}=x_{\max }+\Delta x^{\prime} .
$$

An upgraded intelligent robot [13] with 4 degrees of freedom for experimental investigations of different removable grippers and developed slip displacement sensors is presented at Fig. 14.

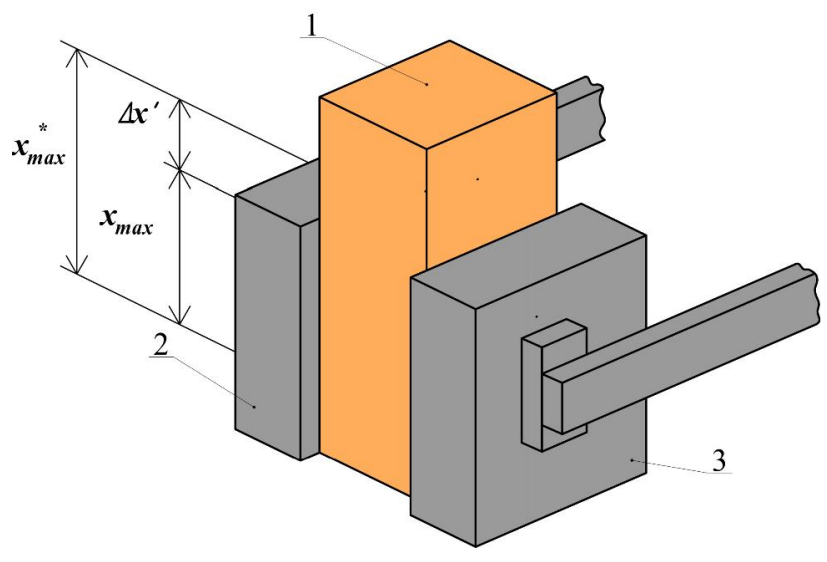

Fig. 13 - Initial positions of the object (1) and the gripper jaws $(2,3)$ before lifting

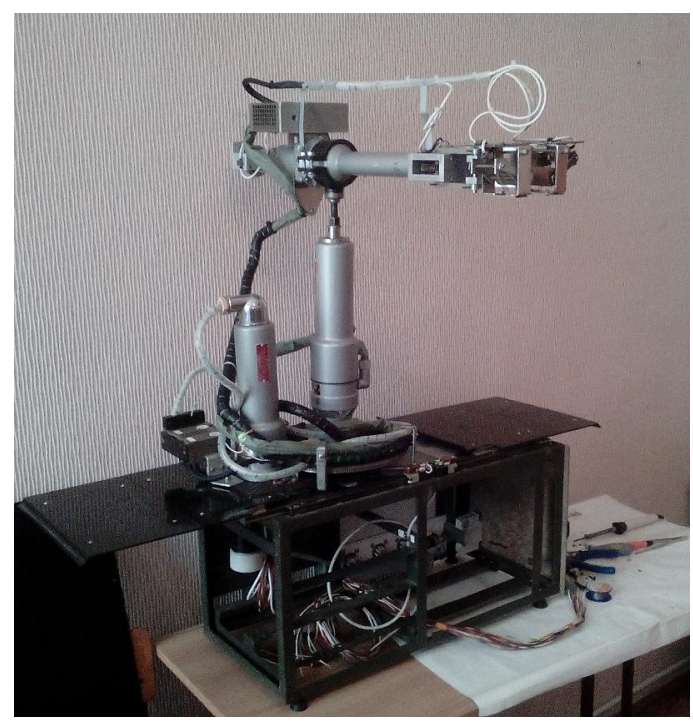

Fig. 14 - Intelligent robot with 4 degree of freedoms for experimental investigations of SDSs 


\section{CONCLUSIONS}

The sensor for the slip signals detection with multifunctional registration elements developed by the authors allows to reduce its functioning dependence from external influences. New sensor features expand its application field for slip signals' registration, particularly for operations with different type's objects, including brittle, and for various industrial manufacturing operations in aggressive environments.

The additional structural elements can improve the sensor performance by reducing time duration between adaptive robot trial motions and speed up the details capturing process before the first trial motion.

The real time testing of the proposed sensor system based on developed SDS with multifunctional conductive rubber registration element was performed on printed circuit board. The designed system is very low cost and easy to manufacture. Temporal characteristics for different conductive plate's sensitivity were obtained with the Proteus software.

The problem of the slip displacement direction identification is solved using FPGA and VHDL languige. The intellectual properties of the proposed sensing system can reduce the time between series of trial motions by maximum movement increasing, so, its resulting operation speed increases.

Optimal calculating algorithm capable for definition of the ratio between such parameters as: square wave generator frequency, storage capacitor charging time, comparator threshold and volume electrical resistance (consided properties of conductive rubber) - is planned in future work.

\section{REFERENCES}

[1] Y.G. Kozyirev, Industrial Robots, Handbook, 2nd ed., revised and enlarged, Moscow: Publisher Mashinostroenie, 1988, 392 p. (in Russian).

[2] S. Osadchy, V. Zozulya, A. Timoshenko, "The dynamic characteristics of the manipulator with parallel kinematic structure based on experimental data," in Proceedings of the 2013 IEEE 7th International Conference on Intelligent Data Acquisition and Advanced Computing Systems (IDAACS), Vol. 2, Berlin, Germany, September 12-14, pp. 905-911.

[3] Y. Kondratenko, A. Topalov, O. Gerasin, "Analysis and modeling of the slip signals' registration processes based on sensors with multicomponent sensing elements," in Proc. of the 13th Int. conf. CADSM 2015, Lviv, Ukraine, February 24-27, 2015, pp. 109-112. DOI: 10.1109/CADSM.2015.7230810.
[4] A. N. Tkachenko, N. M. Brovinskaya, Y.P. Kondratenko, "Evolutionary adaptation of control processes in robots operating in nonstationary environments," Mechanism and Machine Theory, Vol. 18, No. 4, Printed in Great Britain, pp. 275-278, 1983. DOI: 10.1016/0094-114X(83)90118-0

[5] D. Souto, A. Faiña, F. López Peña, R. J. Duro, "Lappa: a new type of robot for underwater non-magnetic and complex hull cleaning," IEEE Int. Conf. on Robotics and Automation (ICRA), Karlsruhe, May 6-10, 2013, pp. 33943399.

[6] Y.P. Kondratenko, O.V. Kozlov, O.S. Gerasin, Y.M. Zaporozhets, "Synthesis and research of neuro-fuzzy observer of clamping force for mobile robot automatic control system," in Proc. of the 2016 IEEE First Int. Conf. on Data Stream Mining \& Processing (DSMP), Lviv, Ukraine, August 23-27, 2016. - pp. 90-95. DOI: 10.1109/DSMP.2016.7583514.

[7] D. Souto, A. Faiña, A. Deibe, F. López-Peña, R.J. Duro, "A robot for the unsupervised gritblasting of ship hulls," Int. J. of Advanced Robotic Systems, Vol. 9, 82, pp. 1-16, 2012.

[8] Y. Kondratenko, E. Shvets, O. Shyshkin, "Modern sensor systems of intelligent robots based on the slip displacement signal detection," in Ann. of DAAAM for 2007 \& Proc. of the 18th Int. DAAAM Symp. Intelligent Manufacturing and Automation, Vienna, Austria, 2007, pp. 381-382.

[9] D. Roy, Grip Force and Slip Analysis in Robotic Grasp: New Stochastic Paradigm Through Sensor Data Fusion, in: J.G. Rocha, S. Lanceros-Mendez (Eds.), Sensors, Focus on Tactile, Force and Stress Sensors, Vienna, 2008, pp. 217-252.

[10] Y. Kondratenko, L. Klymenko, V. Kondratenko, G. Kondratenko, E. Shvets, "Slip displacement sensors for intelligent robots: solutions and models," in Proc. of the 2013 IEEE 7th Int. Conf. on Intelligent Data Acquisition and Advanced Computing Systems (IDAACS), Vol. 2, Berlin, Germany, September 12-14, 2013, pp. 861-866. DOI: 10.1109/IDAACS.2013.6663050

[11] A. Palagin, V. Opanasenko, "Reconfigurable computing technology," J. Cybernetics and Systems Analysis, Springer, Vol. 43, No. 5, New York, pp. 675-686, 2007.

[12] A. Drozd, V. Kharchenko, S. Antoshchuk, J. Sulima, M. Drozd, "Checkability of the digital components in safety-critical systems: problems and solutions," in Proc. IEEE EastWest Design and Test Symposium, EWDTS'2011, 2011, pp. 411-416. 
[13] Y.P. Kondratenko and V.Y. Kondratenko, Advanced trends in design of slip displacement sensors for intelligent robots, in: Y. Kondratenko, R. Duro (Eds.), Advances in Intelligent Robotics and Collaborative Automation, River Publishers Series in Automation, Control and Robotics, 2015, pp. 167-192.

[14] A.M. Zaki, O.A. Mahgoub, A.M. El-Shafei, A.M. Soliman, "Design and implementation of efficient intelligent robotic gripper," WSEAS Transactions on Systems, November, Vol. 9, Issue 11, pp. 1130-1142, 2010.

[15] S. Chakraborty, S. Kumari, "Design and development of a magneto-optic sensor for magnetic field measurements," Sensors \& Transducers, Vol. 184, Issue 1, pp. 153-158, January 2015.

[16] P. Gan, G. Hu, Z. Li, Z. Chen, X. Cheng, H. Huang, X. Zhang, "The algorithm on displacement differences calculation and the error of surface displacement measuring device," Sensors \& Transducers, Vol. 162, Issue 1, pp. 167-172, January 2014.

[17] T. D'Alessio, R. Steindler, "Slip sensors for the control of the grasp in functional neuromuscular stimulation," Med. Eng. Phys., Vol. 17, No. 6, pp. 466-470, 1995.

[18] V.N. Dubey, R.M. Crowder, "A dynamic tactile sensor on photoelastic effect," Sensors and Actuators, A 128, pp. 217-224, 2006.

[19] G. Cannata, M. Maggiali, Design of a tactile sensor for robot hands, in: J.G. Rocha, S. Lanceros-Mendez (Eds.), Sensors, Focus on Tactile, Force and Stress Sensors, Vienna, 2008, pp. 271-288.

[20] F. Xu, Yu. Ge, Y. Yu, J. Ding, T. Ju, S. Li, "The design of a novel flexible tactile sensor based on pressure-conductive rubber," Sensors \& Transducers, Vol. 124, Issue 1, pp. 19-29, January 2011.

[21] R. D. Ponce Wonga, J.D. Posner, V.J. Santos, "Flexible microfluidic normal force sensor skin for tactile feedback," Sensors and Actuators, A 179, pp. 62-69, 2012.

[22] P.S. Girão, P.M.P. Ramos, O. Postolache, J.M.D. Pereira, "Tactile sensors for robotic applications," Measurement, Vol. 46, pp. 12571271, 2013.

[23] Y.P. Kondratenko, O.S. Gerasin, A.M. Topalov, "Modern sensing systems of intelligent robots based on multi-component slip displacement sensors," in Proc. of the 2015 IEEE 8th Int. Conf. on Intelligent Data Acquisition and Advanced Computing Systems: Technology and Applications (IDAACS), Vol. 2, Warsaw, Poland, September 24-26, 2015, pp.
902-907.

DOI:

10.1109/IDAACS.2015. 7341434

[24] D. Gunji, Y. Mizoguchi, S. Teshigawara, A. Ming, A. Namiki, M. Ishikawa, M. Shimojo, "Grasping force control of multi-fingered robot hand based on slip detection using tactile sensor," SICE Annu. Conf. the University Electro-Communications, Japan 2008, August, 2008, pp. 894-899.

[25] A. Drimus, G. Kootstra, A. Bilberg, D. Kragic, "Design of a flexible tactile sensor for classification of rigid and deformable objects," Robotics and Autonomous Systems, No. 62, pp. 3-15, 2014.

[26] B. G. Baranochnikov, A. A. Blinov, V.S. Zhuravlev, V.A. Kelmi, "The impact of tensile deformation on the properties of conductive rubber," Caoutchouc and Rubber, No. 10, pp. 34-36, 1979. (in Russian).

[27] Y.M. Lahtin, V.P. Leonteva, Materials Science, third ed., revised and enlarged, Moscow: Publisher Mashinostroenie, 1990, 528 p. (in Russian).

[28] Y. M. Zaporozhets, Y. P. Kondratenko, O.S. Shyshkin, "Mathematical model of slip displacement sensor with registration of transversal constituents of magnetic field of sensing element," Technical electrodynamics, No. 4, pp. 67-72, 2012. (in Ukrainian).

[29] M. Dorozhovets, O. Ivahiv, V. Mokritsky, Unifying Converters with Information of Mechatronic Systems, Manual, Lviv: Publisher National University "Lviv Politehnika", 2009, 304 p. (in Ukrainian).

[30] Q. Sheng, G. Yu Xu, G. Liu, "Design of PZT micro-displacement acquisition system," Sensors \& Transducers, Vol. 182, Issue 11, pp. 119-124, November 2014.

[31] A. Cranny, D.P.J. Cotton, P.H. Chappell, S.P. Beeby, N.M. White, "Thick-film force and slip sensors for a prosthetic hand," Sensors and Actuators, Vol. 123-124, pp. 162-171, 2005.

[32] V.L. Shilo, Functional analog integrated circuit chips, Radio i svyaz, Moscow, 1982, 128 p. (in Russian).

[33] P.J. Zeno, "Emulating the functionality of rodents' neurobiological navigation and spatial cognition cells in a mobile robot," International Journal of Computing, Vol. 14, Issue 2, pp. 7786, 2015.

[34] J. Sieck, V. Yatskiv, A. Sachenko, T. Tsavolyk, "Two-dimensional error control based on modular correcting codes," International Journal of Computing, Vol. 14, Issue 4, pp. 208-215, 2015.

[35] V. Hahanov, K. L. Man, B. A. A. Abbas, E. Litvinova, S. Chumachenko, E. G. Lim, 
M. Leach, "An extended HDL SoC TABmodel for diagnosability and repair," in Proc. of the International MultiConference of Engineers and Computer Scientists 2015, Hong Kong, March 18-20, Vol II, 2015, pp. 729-732.

[36] W.M. El-Medany, "GPRS-based remote sensing and climate control system using CMOD CPLD," International Journal of Computing, Vol. 8, Issue 2, pp. 68-73, 2009.

[37] P. Wilson, Design Recipes for FPGAs: Using Verilog and $V H D L$, second ed., Elsevier, Newnes, 2016, $392 \mathrm{p}$.

[38] V.V. Semenets, I.V. Hahanova, V.I. Hahanov, Design of Digital Systems by Using VHDL Language, KHNURE, Kharkov, 2003, 492 p. (in Russian).

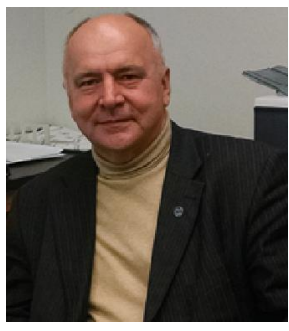

Yuriy Kondratenko, Doctor of Science, Professor, Honour Inventor of Ukraine (2008), Corr. Academician of Royal Academy of Doctors (Barcelona, Spain), Professor of Intelligent Information Systems at Petro Mohyla Black Sea National University, Ukraine. He has received the Ph.D. (1983) and Dr.Sc. (1994) in Elements and Devices of Computer and Control Systems from Odessa National Polytechnic University. He received several international grants and scholarships for conducting research at Institute of Automation of Chongqing University, P.R.China (1988-1989), Ruhr-University
Bochum, Germany (2000, 2010), Nazareth College and Cleveland State University, USA (2003).

He received Fulbright Scholarship for researching in USA (2015/2016) at the Department of Electrical Engineering and Computer Science in Cleveland State University.

His research interests include robotics, automation, sensors and control systems, intelligent decision support systems, control systems, fuzzy logic, elements and devices of computing systems.

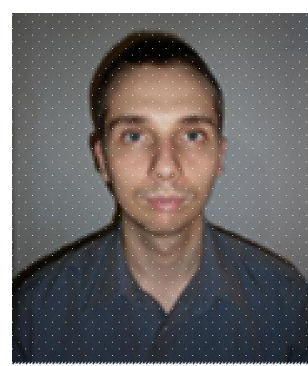

Oleksandr Gerasin, is a PhD student of Admiral Makarov National University of Shipbuilding, Ukraine. He is specialist in control systems for electric actuators. He has gained several diplomas of bachelor and master of electromechanics. His research interests include computer control systems, fuzzy logic, intelligent robotics.

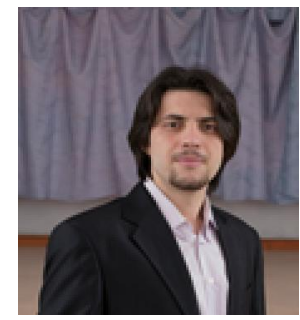

Andriy Topalov, is a PhD student of Admiral Makarov National University of Shipbuilding, Ukraine. He is specialist in electrical engineering. He has gained several diplomas of bachelor and master of electromechanics.

His research interests include computer control systems, sensor systems, fuzzy sets theory, intelligent robotics devices, measurement systems. 